\title{
Emerging strategies in BRCA-positive pancreatic cancer
}

\author{
Adam Kowalewski $^{1} \cdot$ Łukasz Szylberg $^{1,2} \cdot$ Michał Saganek $^{1} \cdot$ Wojciech Napiontek $^{1}$ (D) Paulina Antosik ${ }^{1}$. \\ Dariusz Grzanka ${ }^{1}$
}

Received: 21 March 2018 / Accepted: 14 May 2018 / Published online: 18 May 2018

(c) The Author(s) 2018

\begin{abstract}
Purpose We propose a treatment algorithm for PDAC with particular emphasis on BRCAl or 2 mutation-positive patients. Pancreatic ductal adenocarcinoma (PDAC) is one of the deadliest diseases in the United States and Europe. BRCAl and $B R C A 2$ are among the most common of the known genetic mutations involved in familial PDAC. The optimal chemotherapy regimen to use for $B R C A 1$ or 2 mutation carriers with PDAC is not yet established. As new treatment options emerge, algorithms must balance the need to give the best drugs first with ensuring that there are still beneficial options available for later. Methods We conducted a review of the literature for data on possible therapies in BRCA-positive and BRCA-negative pancreatic cancer.

Results There is accumulating evidence of increased sensitivity to platinum-based therapy and poly-ADP-ribose polymerase inhibitors (PARPi) in BRCA-associated PDAC. There are no studies relating to borderline BRCA-associated PDAC and, therefore, same treatment as for sporadic PDAC seems appropriate. Treatment of unresectable PDAC varies depending on stage of the disease. Patients with $B R C A$-associated locally advanced PDAC can benefit from targeted therapy with PARPi (olaparib) as a second-line therapy after antimetabolite treatment failure. Patients with unresectable metastatic $B R C A$-positive PDAC may benefit from platinum-based therapy.

Conclusion Targeted therapies are shifting the treatment paradigms and increasing survival for patients with PDAC, a group that used to have a grim prognosis.
\end{abstract}

Keywords Pancreatic cancer $\cdot$ BRCA $\cdot$ Mutation $\cdot$ Platinum $\cdot$ PARP inhibitor $\cdot$ Targeted therapy

\section{Introduction}

Pancreatic cancer is one of the deadliest diseases in the United States and Europe, and the fourth leading cause of cancer-related death (Von Hoff et al. 2013). Of all pancreatic cancers, $95 \%$ are adenocarcinomas of the ductal epithelium. The 5-year survival rate for patients with stage IA exocrine pancreatic cancer is about $14 \%$, while in IV stage it does not exceed 1\% (Surgery for Pancreatic Cancer 2016). The identification of molecular mechanism associated with pancreatic

Adam Kowalewski and Łukasz Szylberg contributed equally.

Wojciech Napiontek

wojtek.nap@gmail.com

1 Department of Clinical Pathology, Collegium Medicum in Bydgoszcz, Nicolaus Copernicus University in Torun, Sklodowskiej-Curie Str. 9, 85-094 Bydgoszcz, Poland

2 Department of Pathology, Military Clinical Hospital, Powstańców Warszawy Str. 5, 85-681 Bydgoszcz, Poland carcinogenesis is of utmost importance for understanding the nature of pancreatic cancer (Beger et al. 2004). A family history of pancreatic cancer is found in 5-10\% of pancreatic cancer patients (Klein 2012). Pancreatic ductal adenocarcinoma (PDAC) occurs especially in families with ovarian or breast cancers (Golan et al. 2014).

$B R C A 1$ and BRCA2 are the most common of the known genetic mutations involved in familial pancreatic cancer (Leung and Saif 2013). Family studies have demonstrated that both BRCA1 and BRCA2 mutation carriers have an increased risk of developing pancreatic cancer (Beger et al. 2004). In case of $B R C A 1$ mutation carriers the relative risk for pancreatic cancer is 3.1 and 6.6 in relatives of $B R C A 2$ mutations carriers (Iqbal et al. 2012). Somatic genomic analysis has identified four specific subtypes of pancreatic adenocarcinoma stable, locally rearranged, scattered and unstable (Biankin and Maitra 2015).

$B R C A 1$ and BRCA2 mutations are related to the unstable subtype exhibiting a unique mutational signature reflecting 
DNA damage repair deficiency (Golan et al. 2014). The emergence of molecular tests allows us to tailor treatment strategies based on the presence of driver mutations.

Patients with breast or ovarian BRCA-related cancer now benefit from targeted therapies in the first line and beyond. However, the optimal chemotherapy regimen to use for BRCAl or 2 mutation carriers with PDAC is not yet established. As new treatment options emerge, algorithms must balance the need to give the best drugs first with ensuring that there are still beneficial options available for later. This paper discusses treatment approaches for patients with unresectable PDAC, especially in patients with $B R C A$-related PDAC.

\section{BRCA mutation}

Both BRCA1 and BRCA2 are tumor suppressor genes (Leung and Saif 2013).

Mutations of these genes may play a pivotal role in tumor genesis and cancer progression (Zhu et al. 2017).

Prevalence of BRCA1 and BRCA2 mutations fluctuates between 1 in 300 and 1 in 800 and depends on the population. There are more than 2000 known mutations in BRCAI or 2 genes. In some populations founder mutations are the most frequent. For example, about $2.5 \%$ of the general Ashkenazi Jewish population will harbor mutation of BRCA1. The founder mutations also occur in Northern, Western and Eastern Europe. For that time penetration is variable and not expressly understood (Paluch-Shimon et al. 2016).

Cells with reduced activity of BRCA1 or 2 proteins accumulate double-strand breaks that cause genomic instability and consequently increased predisposition to malignant transformation and progression. Somatic, biallelic inactivation of the BRCAl or 2 genes confers sensitivity to inhibition of poly(ADP-ribose)-polymerase (PARP), an enzyme involved in base excision repair (Beger et al. 2004).

Cell with dysfunction in BRCA1 or 2 genes use less accurate mechanism to repair double-strand breaks which increase the probability of cell death (Solomon and Everett 1990).

\section{Discussion}

The optimal chemotherapy regimen to use for BRCAl or 2 mutation carriers with pancreatic adenocarcinoma is not established. Ryan et al. suggest using the same chemotherapy regimens in the adjuvant setting as are used for nonmutation carriers (Ryan et al. 2018). However, there is accumulating evidence of increased sensitivity to platinum-based therapy and poly-ADP-ribose polymerase inhibitors (PARPi) in BRCA-associated PDAC (Ryan et al. 2018).

Among tested agents these two represent a promising alternative for BRCA-associated PDAC. Seven studies (Golan et al.
2014; Oettle et al. 2014; Kaufman et al. 2015; Wu et al. 2015; Hurt et al. 2017; Kobayashi et al. 2017; Xu et al. 2017) that investigated a predictive role of $B R C A 1$ or 2 mutation among patients with pancreatic cancer are summarized in Table 1 . Most of them showed significantly enhanced response to DNA damage-related agents.

\section{Platinum agents}

In three studies (Oettle et al. 2014; Kaufman et al. 2015; Hurt et al. 2017), there was reported significantly improved OS and response to platinum-based treatment in BRCA-positive PDAC. Platinum-based anticancer drugs bind directly to DNA, causing DNA double-strand breaks. Therefore, cells that lack BRCA1 or BRCA2 have a deficiency in the repair of DNA double-strand breaks (Lohse et al. 2016).

\section{PARP inhibitors}

The PARP enzymes play critical roles in DNA damage detection and repair (de Bono et al. 2017).

PARP1 is a protein that is important for repairing singlestrand breaks. If the breaks persist unrepaired until DNA is replicated, then the replication itself can cause double-strand breaks to form. PARP1 inhibitors cause multiple double-strand breaks to form in this way, and in tumors with BRCAl or 2 mutations, these double-strand breaks cannot be efficiently repaired, leading to death of the cells (Vinayak and Ford 2010).

\section{Therapy}

\section{Resection}

In the early stage of PDAC, surgery offers the only realistic chance for recovery (Surgery for Pancreatic Cancer 2016). Regardless of the use of platinum compounds or PARPi, the prognosis of surgically resectable $B R C A$-associated PDAC is no different than that of sporadic PDAC (Golan et al. 2017). There are no studies relating to borderline $B R C A$-associated PDAC and, therefore, same treatment as for sporadic PDAC seems appropriate (Lopez et al. 2014). Treatment of unresectable PDAC varies depending on stage of the disease. In the following, we separate locally advanced from metastatic tumors.

\section{Unresectable locally advanced $B R C A$ -positive PDAC}

\section{First-line therapy}

There are no studies confirming the greater efficiency of any alternative therapy in patients with unresectable locally 
Table 1 Studies investigating a predictive role of BRCA1 or 2 mutation among patients with pancreatic ductal adenocarcinoma (PDAC)

\begin{tabular}{|c|c|c|c|c|c|}
\hline & Characteristic of patients & No. of patients & Type of therapy & Results & References \\
\hline \multirow[t]{5}{*}{ Locally advanced PC } & \multirow[t]{2}{*}{ Patients with advanced PC } & 36 & Capecitabine + RT & $\begin{array}{l}\mathrm{OS}=17.6 \text { months } \\
\mathrm{PFS}=12 \text { months }\end{array}$ & \multirow[t]{2}{*}{$\begin{array}{l}\text { Hurt et al. } \\
\quad(2017)\end{array}$} \\
\hline & & 38 & Gemcitabine + RT & $\begin{array}{l}\mathrm{OS}=14.6 \text { months } \\
\mathrm{PFS}=10.4 \text { months }\end{array}$ & \\
\hline & $\begin{array}{l}\text { Patients with } B R C A 1 \text { or } 2 \text { mutation } \\
\text { and advanced PDAC, after gemcit- } \\
\text { abine treatment failure }\end{array}$ & 23 & PARPi (olaparib) & $\begin{array}{l}\mathrm{OS}=9.8 \text { months } \\
\mathrm{PFS}=4.6 \text { months }\end{array}$ & $\begin{array}{l}\text { Kaufman } \\
\text { et al. } \\
(2015)\end{array}$ \\
\hline & \multirow{2}{*}{$\begin{array}{l}\text { Patients with advanced } \\
\text { PC after gemcitabine treatment } \\
\text { failure }\end{array}$} & 76 & Oxaliplatin + FA + FU & $\begin{array}{l}\mathrm{OS}=5.9 \text { months } \\
\mathrm{PFS}=2.9 \text { months }\end{array}$ & \multirow{2}{*}{$\begin{array}{l}\text { Oettle } \\
\text { et al. } \\
(2014)\end{array}$} \\
\hline & & 84 & $\mathrm{FA}+\mathrm{FU}$ & $\begin{array}{l}\mathrm{OS}=3.3 \text { months } \\
\mathrm{PFS}=2.0 \text { months }\end{array}$ & \\
\hline \multirow[t]{5}{*}{ Metastatic PC } & \multirow{2}{*}{$\begin{array}{l}\text { Patients with } B R C A 1 \text { or } 2 \text { mutation } \\
\text { and stage III/IV PDAC }\end{array}$} & 22 & Platinum based adjuvant therapy & $\mathrm{OS}=22$ months & \multirow{2}{*}{$\begin{array}{l}\text { Golan } \\
\text { et al. } \\
\text { (2014) }\end{array}$} \\
\hline & & 21 & Non-platinum therapy & $\mathrm{OS}=9$ months & \\
\hline & Patients with metastatic PC & 83 & Gemcitabine + paclitaxel & $\begin{array}{l}\mathrm{OS}=9.2 \text { months } \\
\mathrm{PFS}=5.5 \text { months }\end{array}$ & $\begin{array}{l}\text { Xu et al. } \\
\text { (2017) }\end{array}$ \\
\hline & $\begin{array}{l}\text { Patients with metastatic } \mathrm{PC} \text { after } \\
\text { gemcitabine treatment failure }\end{array}$ & 18 & FOLFIRINOX & $\begin{array}{l}\mathrm{OS}=9.8 \text { months } \\
\mathrm{PFS}=2.8 \text { months }\end{array}$ & $\begin{array}{l}\text { Kobayashi } \\
\text { et al. } \\
(2017)\end{array}$ \\
\hline & $\begin{array}{l}\text { Patients with metastatic } \\
\text { PC after gemcitabine treatment } \\
\text { failure }\end{array}$ & 17 & Lapatinib + capecitabine & $\begin{array}{l}\mathrm{OS}=5.2 \text { months } \\
\mathrm{PFS}=2.6 \text { months }\end{array}$ & $\begin{array}{l}\text { Wu et al. } \\
(2015)\end{array}$ \\
\hline
\end{tabular}

$P C$ pancreatic cancer, $P D A C$ pancreatic ductal adenocarcinoma, $R T$ radiotherapy, $P A R P i$ poly(ADP-ribose)-polymerase inhibitor, $F A$ folinic acid, $F U$ fluorouracil, $O S$ overall survival, $P F S$ progression-free survival

advanced $B R C A$-related PDAC as a first-line therapy. Antimetabolites appear to be the best option as a first-line therapy. Hurt et al. tested the activity and safety of gemcitabinebased and capecitabine-based chemoradiation for locally advanced pancreatic cancer. mOS was 17.6 months among patients treated with capecitabine-based chemoradiation vs 14.6 months among patients with gemcitabine-based chemoradiation. Also mPFS was higher in group treated with capecitabine-based chemoradiaton (12.0 vs 10.4 months in group treated with gemcitabine-based chemoradiation) (Hurt et al. 2017).

\section{Second-line therapy}

Patients with $B R C A$-associated locally advanced pancreatic cancer can benefit from targeted therapy with PARP inhibitor (olaparib) as a second-line therapy after antimetabolite treatment failure. Leung and Saif described an example of two patients with BRCA2-associated pancreatic cancer treated with PARP inhibitors. Patients achieved partial or complete response with non-significant side effects (Leung and Saif 2013). The distinct sensitivity of cancerous cells to PARPi (olaparib) was also observed in study of Lowery et al. (2011). Among 16 cases, 11 had BRCA2-associated PDAC. Three out of four patients receiving PARPi and five out of six patients receiving platinum-based chemotherapy demonstrated an initial radiographic partial response. Unfortunately, each patient treated with a PARP inhibitor experienced progression of disease after several months of therapy. It was probably caused by acquired resistance to PARP inhibition.

Similar study showed that tumor response rate for patients treated with PARPi was $21.7 \%$. OS in this group was 9.8 months and PFS was 4.6 months. Severe side effects (grade 3 or 4 ) were observed in $30.4 \%$ of patients. There was no significant difference in response rate for those treated previously with platinum or between $B R C A 1$ and $B R C A 2$ mutation. Type of mutation appeared to be not as important as previously suspected. Moreover, prior platinum treatment does not improve patients' outcomes (Kaufman et al. 2015). Oettle et al. used oxaliplatin, folinic acid (FA) and fluorouracil (FU) also after gemcitabine therapy failure. The data regarding $B R C A$ mutation are not applicable. OS in this group was 5.9 months and PFS was 2.9 months. Severe side effects (grade 3 or 4) were observed in $43 \%$ of patients (Oettle et al. 2014).

\section{Third-line therapy}

There is no established third-line therapy for patients with $B R C A$-positive PDAC. We suggest using the standard 
second-line treatment. Treatment with oxiplatine together with FA and FU as a second line, results in OS of 5.9 months (Oettle et al. 2014).

\section{Unresectable metastatic BRCA-positive PDAC}

\section{First-line therapy}

Patients with unresectable metastatic $B R C A$-positive PDAC may benefit from platinum-based therapy. Golan et al. compared platinum-based therapy vs non-platinum chemotherapies in patients with $B R C A$-positive pancreatic cancer in stage III/IV. Median overall survival (mOS) in patients treated with platinum agents was higher comparing to those treated with non-platinum chemotherapies (22 vs 9 months, $P=0.039$ ). This study also showed that probability of OS in patients treated with platinum is 0.7 in 12 months and 0.16 in 36 months. Probability of OS in patients treated with non-platinum chemotherapy is 0.26 in 12 months and 0.07 in 36 months (Golan et al. 2014).

\section{Second-line therapy}

There is no established second-line therapy for patients with $B R C A$-positive PDAC after platinum-based therapy. Therefore, treatment with gemcitabine with paclitaxel or erlotynib or capecitabine is a reasonable option. Xu et al. conducted a study using gemcitabine with paclitaxel in patients with metastatic pancreatic cancer. In this study, mOS was 9.2 months and median progression-free survival (PFS) was 5.5 months. The most common grade $\geq 3$ adverse events were leukopenia (35\%), neutropenia (34\%), anemia (15\%), thrombocytopenia (10\%), and fatigue (13\%) (Xu et al. 2017).

\section{Third-line therapy}

There is no established third-line therapy for patients with BRCA-positive PDAC. Selection of the therapy after gemcitabine treatment failure depends on patient's condition and life expectancy. Kobayashi et al. studied the effectiveness of FOLFIRINOX in patients with metastatic pancreatic cancer after gemcitabine treatment failure. Among 18 patients receiving FOLFIRINOX, mOS was 9.8 months and PFS was 2.8 months (Kobayashi et al. 2017). Because of high rate of serious side effects (78\%), such treatment is recommended especially in patients in good health. Wu et al. studied the effectiveness of lapatinib and capecitabine in patients with metastatic pancreatic cancer after gemcitabine treatment failure. mOS and PFS was lower than after FOLFIRINOX (5.2 vs 9.8 months and 2.6 vs 2.8 months, respectively). However, serious side effects were observed only in $18 \%$ of patients (Wu et al. 2015). This is why lapatinib and capecitabine seem the most accurate in patients with serious side effects after gemcitabine treatment.

\section{Conclusions}

Our understanding of PDAC mutations and their contribution to therapeutic efficacy is expanding. The treatment selection is complex, with new target therapies being developed. Because BRCAI and BRCA2 mutations are relatively rare in the general population, testing should be performed especially when the person's individual or family history suggests the possible presence of a harmful mutation in

Fig. 1 Treatment algorithm for pancreatic ductal adenocarciUnresectable PDAC noma (PDAC) patients. BRCA1 or 2 mutation determines the optimal therapy

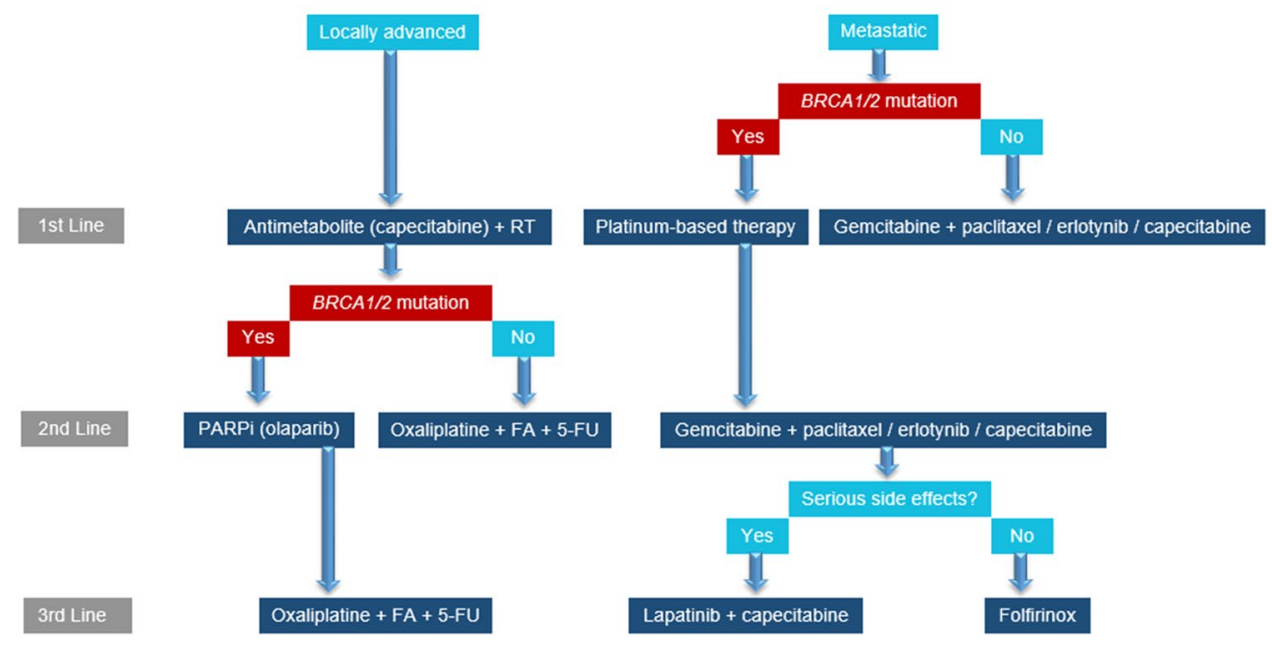


$B R C A 1$ or $B R C A 2$. For patients with locally advanced PDAC with $B R C A 1$ or 2 mutation who have progressed on capecitabine, new treatment options to improve survival include PARP inhibitors such as olaparib. For patients with metastatic PDAC with $B R C A 1$ or 2 mutation, platinum-based therapy can lead to significant improvements in survival. Targeted therapies are shifting the treatment paradigms and increasing survival for patients with PDAC, a group that used to have a grim prognosis. We propose a treatment algorithm for PDAC with particular emphasis on BRCAl or 2 mutation-positive patients (Fig. 1).

Author contributions All authors contributed in a manuscript as well as figure preparation are thoroughly familiar with its present version and are able to defend its content and conclusions.

\section{Compliance with ethical standards}

Conflict of interest The authors declare that they have no conflict of interest.

Ethical approval This article does not contain any studies with human participants or animals performed by any of the authors.

Open Access This article is distributed under the terms of the Creative Commons Attribution 4.0 International License (http://creativeco mmons.org/licenses/by/4.0/), which permits unrestricted use, distribution, and reproduction in any medium, provided you give appropriate credit to the original author(s) and the source, provide a link to the Creative Commons license, and indicate if changes were made.

\section{References}

Beger C et al (2004) Down-regulation of BRCA1 in chronic pancreatitis and sporadic pancreatic adenocarcinoma. Clin Cancer Res 10(11):3780-3787. https://doi.org/10.1158/1078-0432. CCR-0992-3

Biankin AV, Maitra A (2015) Subtyping pancreatic cancer. Cancer Cell 28(4):411-413. https://doi.org/10.1016/j.ccell.2015.09.020

de Bono J et al (2017) 'Phase I, dose-escalation, two-part trial of the PARP inhibitor Talazoparib in patients with advanced germline BRCA1/2 mutations and selected sporadic cancers.', Cancer discovery. Am Assoc Cancer Res 7(6):620-629. https://doi. org/10.1158/2159-8290.CD-16-1250

Golan T et al (2014) Overall survival and clinical characteristics of pancreatic cancer in BRCA mutation carriers. Br J Cancer 111(6):1132-1138. https://doi.org/10.1038/bjc.2014.418

Golan T et al (2017) Overall survival and clinical characteristics of BRCA mutation carriers with stage I/II pancreatic cancer. Br J Cancer 116(6):697-702. https://doi.org/10.1038/bjc.2017.19

Hurt CN et al (2017) Long-term results and recurrence patterns from SCALOP: a phase II randomised trial of gemcitabine- or capecitabine-based chemoradiation for locally advanced pancreatic cancer. Br J Cancer 116(10):1264-1270. https://doi.org/10.1038/ bjc.2017.95 (Nature Publishing Group)

Iqbal J et al (2012) The incidence of pancreatic cancer in BRCA1 and BRCA2 mutation carriers. Br J Cancer 107(12):2005-2009. https ://doi.org/10.1038/bjc.2012.483
Kaufman B et al (2015) Olaparib monotherapy in patients with advanced cancer and a germline BRCA $1 / 2$ mutation. J Clin Oncol 33(3):244-250. https://doi.org/10.1200/JCO.2014.56.2728 (American Society of Clinical Oncology)

Klein AP (2012) Genetic susceptibility to pancreatic cancer. Mol Carcinog 51(1):14-24. https://doi.org/10.1002/mc.20855

Kobayashi $\mathrm{N}$ et al. (2017) Effect of FOLFIRINOX as second-line chemotherapy for metastatic pancreatic cancer after gemcitabinebased chemotherapy failure. https://doi.org/10.1097/MD.00000 00000006769

Leung K, Saif MW (2013) BRCA-associated pancreatic cancer: the evolving management. JOP: Journal of the pancreas 14(2):149 151. http://www.ncbi.nlm.nih.gov/pubmed/23474559. Accessed 14 Jan 2018

Lohse I et al (2016) 'Effects of combined treatment with ionizing radiation and the PARP inhibitor olaparib in BRCA mutant and wild type patient-derived pancreatic cancer xenografts'. PLoS One 11(12):1-11. https://doi.org/10.1371/journal.pone.0167272

Lopez NE, Prendergast C, Lowy AM (2014) Borderline resectable pancreatic cancer: definitions and management. World J Gastroenterol 20(31):10740-10751. https://doi.org/10.3748/wjg.v20.i31.10740

Lowery MA et al (2011) An emerging entity: pancreatic adenocarcinoma associated with a known BRCA mutation: clinical descriptors, treatment implications, and future directions. Oncologist 16(10):1397-1402. https://doi.org/10.1634/theoncologist.20110185 (AlphaMed Press)

Oettle H et al (2014) Second-line oxaliplatin, folinic acid, and fluorouracil versus folinic acid and fluorouracil alone for gemcitabinerefractory pancreatic cancer: outcomes from the CONKO-003 trial. J Clin Oncol 32(23):2423-2429. https://doi.org/10.1200/ JCO.2013.53.6995

Paluch-Shimon S et al (2016) Prevention and screening in BRCA mutation carriers and other breast/ovarian hereditary cancer syndromes: ESMO Clinical Practice Guidelines for cancer prevention and screening †. Ann Oncol 27(suppl_5):v103-v110. https://doi. org/10.1093/annonc/mdw327

Ryan D et al (2018) Treatment for potentially resectable exocrine pancreatic cancer. uptodate.com. https://www.uptodate.com/contents/ treatment-for-potentially-resectable-exocrine-pancreatic-cancer. Accessed 14 Jan 2018

Solomon P, Everett WD (1990) Gynecologic core conference in a family practice residency. Fam Med 22(3):239-240. http://www.ncbi. nlm.nih.gov/pubmed/2347455. Accessed 14 Jan 2018

Surgery for Pancreatic Cancer (2016). https://www.cancer.org/cance r/pancreatic-cancer/treating/surgery.html. Accessed 29 Jan 2018

Vinayak S, Ford JM (2010) PARP inhibitors for the treatment and prevention of breast cancer. Curr Breast Cancer Rep 2(4):190-197. http://www.ncbi.nlm.nih.gov/pubmed/22655123 (Accessed 9 Nov 2017) (NIH Public Access)

Von Hoff DD et al (2013) Increased survival in pancreatic cancer with nab-paclitaxel plus gemcitabine. New Engl J Med 369(18):16911703. https://doi.org/10.1056/NEJMoa1304369 (Massachusetts Medical Society)

Wu Z et al (2015) Phase II study of lapatinib and capecitabine in second-line treatment for metastatic pancreatic cancer. Cancer Chemother Pharmacol 76(6):1309-1314. https://doi.org/10.1007/s0028 $0-015-2855-\mathrm{z}$

Xu R et al (2017) Efficacy and safety of weekly nab-paclitaxel plus gemcitabine in Chinese patients with metastatic adenocarcinoma of the pancreas: a phase II study. BMC cancer. https://doi. org/10.1186/s12885-017-3887-z

Zhu Y et al (2017) BRCA1 missense polymorphisms are associated with poor prognosis of pancreatic cancer patients in a Chinese population. Oncotarget 8(22):36033-36039. https://doi. org/10.18632/oncotarget.16422 